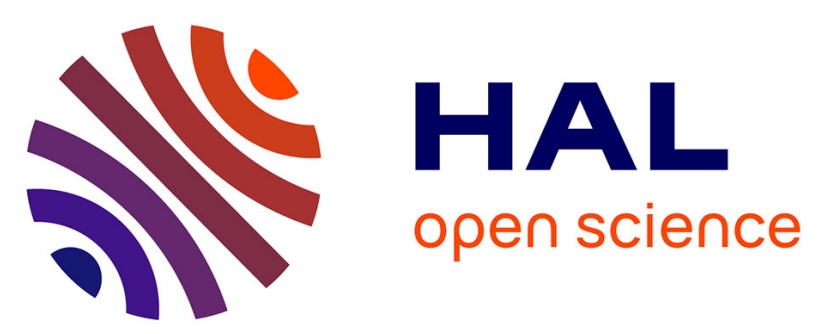

\title{
Cell repellent coatings on inner walls of tubes by means of transporting discharge in atmospheric pressure.
}

A Valinataj Omran, Jérôme Pulpytel, F Sohbatzadeh, M Mirshahi, Farzaneh Arefi-Khonsari

\section{- To cite this version:}

A Valinataj Omran, Jérôme Pulpytel, F Sohbatzadeh, M Mirshahi, Farzaneh Arefi-Khonsari. Cell repellent coatings on inner walls of tubes by means of transporting discharge in atmospheric pressure.. Plasma Chemistry and Plasma Processing, 2019, Plasma Chemistry and Plasma Processing, 39 (5), pp.1181-1190. 10.1007/s11090-019-10000-1 . hal-02136471

\section{HAL Id: hal-02136471 \\ https://hal.science/hal-02136471}

Submitted on 22 May 2019

HAL is a multi-disciplinary open access archive for the deposit and dissemination of scientific research documents, whether they are published or not. The documents may come from teaching and research institutions in France or abroad, or from public or private research centers.
L'archive ouverte pluridisciplinaire HAL, est destinée au dépôt et à la diffusion de documents scientifiques de niveau recherche, publiés ou non, émanant des établissements d'enseignement et de recherche français ou étrangers, des laboratoires publics ou privés. 


\title{
Cell repellent coatings on inner walls of tubes by means of transporting discharge in atmospheric pressure
}

\author{
A. Valinataj Omran ${ }^{1,3, *}$, J. Pulpytel ${ }^{1}$, F. Sohbatzadeh ${ }^{3}$, M. Mirshahi $^{2}$ and F. Arefi-Khonsari ${ }^{1}$ \\ 1 Laboratoire Interfaces et Systèmes Electrochimiques, LISE, CNRS, Sorbonne Université, 75005 Paris, France \\ 2 Sorbonne Paris Cité, UMR Université Paris 7, INSERM U965 Carcinose, Angiogenèse et Recherche \\ Translationnelle, L'Hôpital Lariboisière, 41 Bd de la Chapelle 75010 Paris France \\ 3 Department of Atomic and Molecular Physics, Faculty of Basic Sciences, University of Mazandaran, Babolsar \\ 47416-95447, Mazandaran, Iran \\ * Correspondence: a_valinataj@hotmail.com
}

\begin{abstract}
We report a method to obtain biocompatible PEG copolymer coatings inside High Density Polyethylene (HDPE) and Pyrex tubes, which was successfully developed by using a transporting discharge. The latter being a dry process, it is easier to apply as compared to the conventional multistep wet chemical techniques. The results presented in this paper show that for a $70 \mathrm{~cm}$ tube good cell repellent properties as compared to the control was obtained for the entire length of the tube. The best nonfouling properties with respect to CT-26 (colon cancer) were obtained for coatings presenting the best retention of ether functionalities from the DEGME monomer i.e. between 5-25 cm downstream of the tube. These results are interesting for surface modification of biomaterial and biomedical devices which present hollow bodies.
\end{abstract}

Keywords: Transporting discharge; cell repellent coating; HDPE tube, Pyrex tube, DEGME monomer, Surface modification

\section{Introduction}

The use of cold atmospheric pressure plasmas for developing of organic coatings has extremely increased due to the various requirements of modified surfaces for industrial and domestic applications [1-6]. Film deposition regimes in atmospheric plasmas are mostly based on plasma-enhanced chemical vapor depositions (PECVD). Polymers produced by PECVD are very different from traditional polymers which are chemically regular and represent a repetition of monomer units. Indeed plasma polymers are in most cases characterized by a short range order and highly branched and cross-linked $[7,8]$. But they are rich in functional groups which could be useful as chemical anchors or be used to facilitate interactions with other materials including biological media.

These polymers are well-suited for coating of solids such as membranes, semiconductors, metals, textiles or polymers [9]. For real biomedical applications, however, modification of surfaces of complex shapes may be required such as, inner walls of vascular grafts or catheters that need to be rendered nonfouling for improvement of their performance. The appropriate geometry of cold plasma jets suggests that they may be profitable for this effort. For example, deposition of fluoro-polymer films onto the inner surface of commercial poly vinyl chloride tubing with the aim of increasing its blood compatibility has already been reported [10]. Gordeev et al showed the applicability of the SDBD-based jet with di (ethylene) glycol vinyl ether used as a precursor for deposition of PEO-like plasma polymers in cavities [11].

Poly (ethylene glycol) (PEG) is the most widely used and intensively studied non-ionic, hydrophilic and non-bio adhesive polymer [12]. Due to this reason, PEG has been extensively used for the preparation of anti-fouling surfaces and has been studied as a model surface for the bioactivity of molecules [13]. Because PEG has been clinically FDA approved, it has been widely utilized as a key 
material for the pharmaceutical, food, cosmetic and body care products [14]. The plasma-polymerized PEG coatings exhibit protein- and cell-repellent properties due to their hydrophilicity and tendency to form a water barrier at the surface [15]. Bhatt et al developed a catalyst free strategy to obtain nanosized biocompatible PCL-PEG copolymer coatings by low pressure pulsed plasma copolymerization [16]. In the literature only a few papers have reported successful deposition of PEG-like coatings in atmospheric pressure systems. However the optimal window to obtain a high percentage of C-O-C bondings is always reported to be very narrow. Bhatt et al have deposited PEG like coatings with a CO-C percentage of $50 \%$ which were cell repellent on PS plates [17] by using an open air APPJ in argon. Other groups have also used closed DBD systems in helium [18, 19].

The aim of the present work is to investigate the applicability of the transporting discharge for deposition of PEG coatings by polymerization of DiEthyleneGlycoleDiMethylEther (DEGDME) on the inner walls of HDPE and Pyrex tubes to control the cell-surface interactions for biological applications.

\section{Materials and Methods}

\subsection{Experimental Setup}

We have developed a transporting discharge source that can operate at atmospheric pressure and near room temperature [20]. The plasma device was driven by a homemade power supply with an AC high voltage at $5 \mathrm{kHz}$ superimposed on a DC high voltage. A schematic of the plasma jet is shown in Figure 1. The power supply was connected to the stainless needle electrode which was embedded in the center of a HDPE (high density polyethylene) or Pyrex tube with inner/outer diameters of $6 \mathrm{~mm} / 9 \mathrm{~mm}$ and length of $70 \mathrm{~cm}$ allowing the working gas to flow through. HDPE was chosen because it is commonly used in chemical, biological and medical applications and for cell culture experiments Pyrex tube was used. A copper tape electrode that encircled the outer part of the tube was connected to the ground. Helium working gas was introduced into the annular space. DiEthyleneGlycoleDiMethylEther (DEGDME, Sigma Aldrich, France) precursor was injected before the powered electrode (Figure 1) for depositing PEG films inside the tube. This precursor was used without further purifications. The coatings were deposited on the inner wall of the tubes by introducing He/DEGME mixture with a deposition time of 30 minutes. The deposition conditions used were kept constant as follows: He gas flow rate $=1000 \mathrm{sccm}$, applied power $5 \mathrm{~W}$, and DEGME flow rate $=0.3 \mathrm{sccm}$.

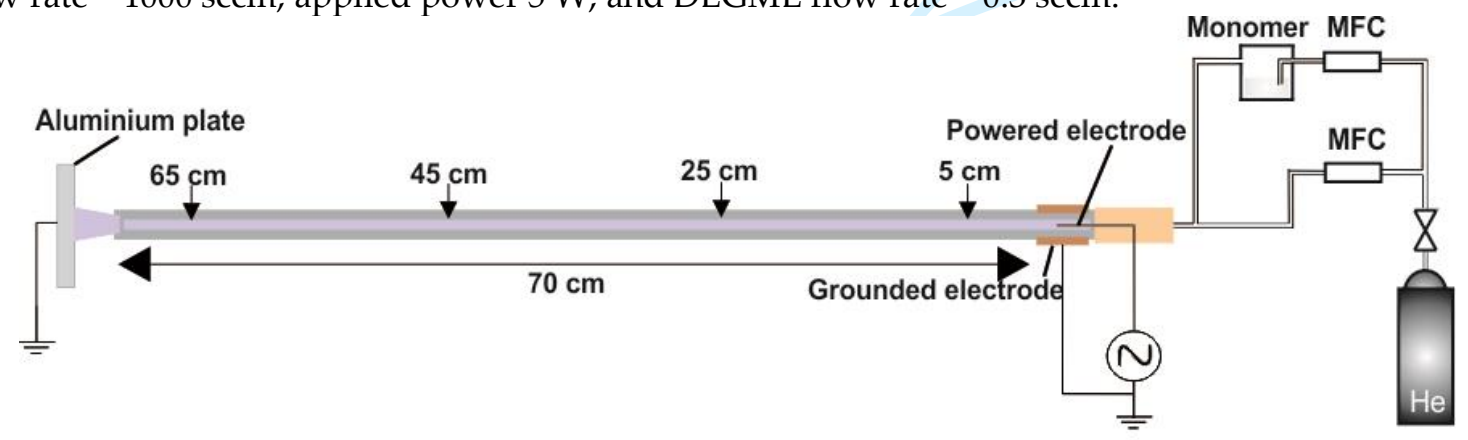

Figure 1. Schematic representation of the transporting discharge deposition system.

\subsection{Surface analysis techniques}

\subsubsection{FTIR-ATR Spectroscopy}

The chemical composition of the films was characterized by using a Bruker VERTEX 70 FT-IR Spectrophotometer equipped with a single reflection ATR accessory using a germanium crystal. 
Infrared absorbance spectra were recorded in the 400-4000 cm-1 range, with a resolution of $4 \mathrm{~cm}-1$ and 200 scans for each sample. The signal of the bare substrate was taken as reference and baseline correction was performed by OPUS 6.5 software.

\subsubsection{X-Ray Photoelectron Spectroscopy (XPS)}

XPS surface analysis of the plasma-polymerized PEG samples was performed on a XPS (Axis Ultra, Kratos, UK) equipped with a monochromatic aluminum $\mathrm{K} \alpha \mathrm{X}$-ray source (1486.6 eV). Casa XPS fitting software was used to curve fit the high resolution C1s peaks. The hydrocarbon component of the C1s spectrum $(285.0 \mathrm{eV})$ was used to calibrate the energy scale. In a second step, the peaks were deconvoluted using the Gaussian curve-fitting technique.

\subsubsection{FE-SEM}

The morphology of UHMWPE films was studied by Field Emission Scanning Electron Microscopy (FE-SEM). FE-SEM images were taken using Zeiss Ultra 55 FEG SEM with GEMINI Column on gold coated surfaces by sputter coating (Cressinton sputter coater-108 auto).

\subsubsection{Cell culture}

Cellular adhesion tests were performed using CT-26 (colon cancer), cultured in Dulbecco's Modified Eagle's Medium (DMEM). The culture medium was supplemented with 1\% (v/v) antibiotics (10,000 U/ml penicillin-G sodium, $10 \mathrm{mg} / \mathrm{ml}$ streptomycin), $2 \mathrm{mM}$ L-glutamine (Fisher scientific, France) and 10\% fetal bovine serum (FBS, Sigma Aldrich, France). Cells were expanded by routine cell culture techniques in $25 \mathrm{~cm} 2$ cell culture flasks containing $5 \mathrm{ml}$ of $10 \%$ serum supplemented medium and were incubated in a humidified atmosphere of 95\% air and 5\% CO2 (Napco, Model 5410,France) at $37^{\circ} \mathrm{C}$ for 24 hours.

When seeded out for experiments, the cells were detached by trypsinisation, pelleted ( $1 \mathrm{ml}$ for 3 min with a table centrifuge (Beckman Coulter, Fullerton, CA, USA)) and resuspended in a complete growth medium. After plasma treatment, the first $60 \mathrm{~cm}$ of Pyrex tube was cut in three $20 \mathrm{~cm}$ pieces and used for cell culturing. The amount of cells in the suspension was counted by using a C-Chip (DHCF01) and then $5 \mathrm{ml}$ of CT-26 cell suspension with a density of 105 cells/ tube was seeded out into each tube and was incubated at physiological conditions for $24 \mathrm{~h}$.

\section{Results}

The films deposited on the different parts of inner walls of the tube were analyzed using a FTIR spectroscopy (Figure 2). The following bands can be identified: a band at $2934 \mathrm{~cm}^{-1}$ and $2967 \mathrm{~cm}^{-1}$ attributed to the vibrational bands of aliphatic hydrocarbon $\mathrm{C}-\mathrm{H}$ stretching bonds, a band located in the $1108 \mathrm{~cm}^{-1}$ region, which results from the $\mathrm{C}-\mathrm{O}-\mathrm{C}$ stretching vibrations of the precursor and finally a band around $1738 \mathrm{~cm}^{-1}$, which is characteristic of $\mathrm{C}=\mathrm{O}$ stretching vibrations. So besides the retention of the C-O-C functions of the DEGME precursor in the coatings, the radicals formed from the fragmentation of the precursor go through reorganization and oxidation assisted by the presence of oxygen excited species as well as $\mathrm{OH}$ radicals from the surrounding medium. The spectral analysis of PEG coatings deposited at different parts of downstream tubes show substantial changes in the chemical composition of the coatings with an increase of the distance from the powered electrode. The intensities of $\mathrm{C}-\mathrm{O}-\mathrm{C}$ and $\mathrm{C}=\mathrm{O}$ bonds are almost constant in the $0-25 \mathrm{~cm}$ region, then the latter dramatically decreased after $45 \mathrm{~cm}$ from the powered electrode, which suggest that the film thickness is decreasing due to the monomer depletion. It has been reported in the literature that the non-fouling behavior of PEG polymers are attributed to the retention of ethylene oxide groups, as followed by the intensity of C-O-C stretching vibrations. 
Figure 2: FTIR spectra of PEG coatings deposited at different downstream parts of the tube $(5 \mathrm{~cm}$ downstream is near the electrode and $65 \mathrm{~cm}$ downstream is near the outlet) and applied power of $5 \mathrm{~W}$.

SEM analyses were used to examine the surface morphologies of the atmospheric-pressure plasma deposited PEG films. The cross section images of a HDPE tube coated by the He/DEGME transporting discharge at different distances downstream from the powered electrode and the surface morphologies of the inner walls coated at different distances are shown on Figure 3. It can be seen that the films have a smooth surface. One can also observe that some peeling of the coatings from the inner tube walls occurred due to the applied pressure when cutting the tube.
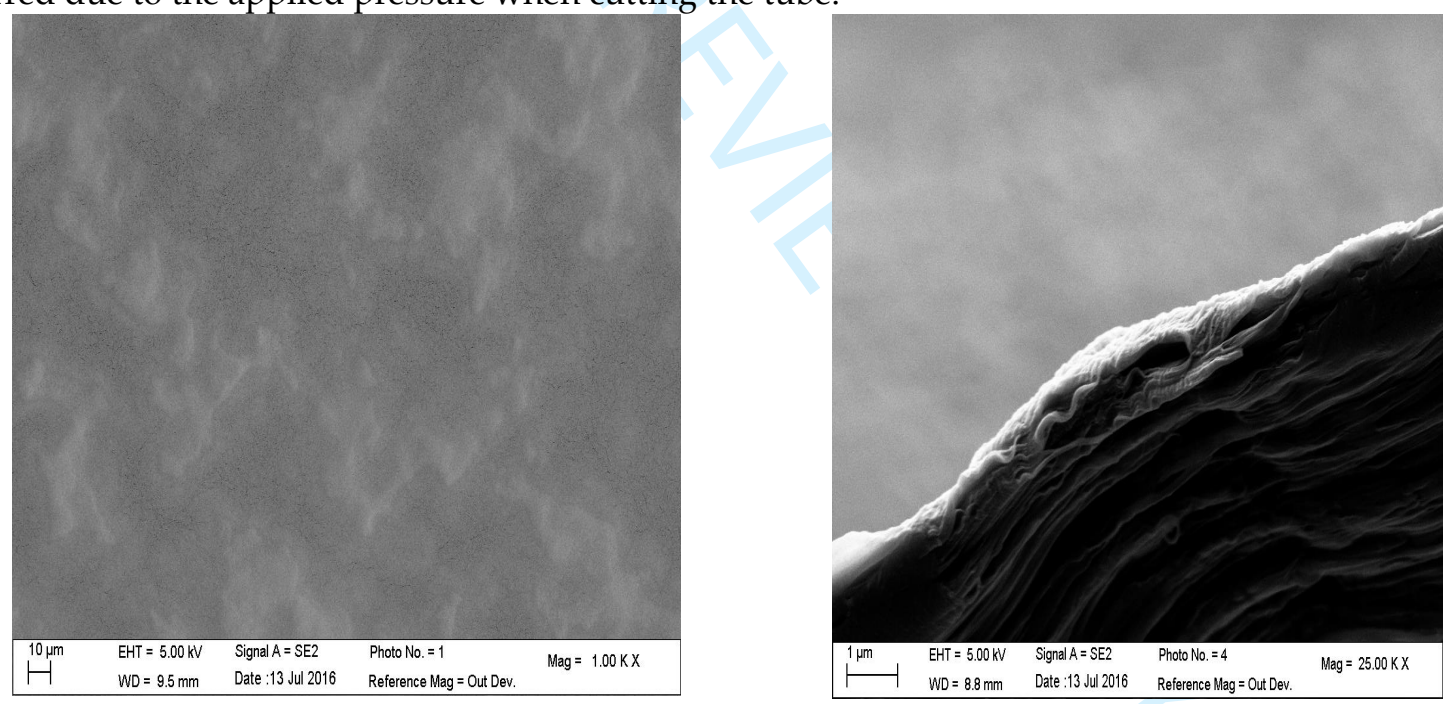

(a) 

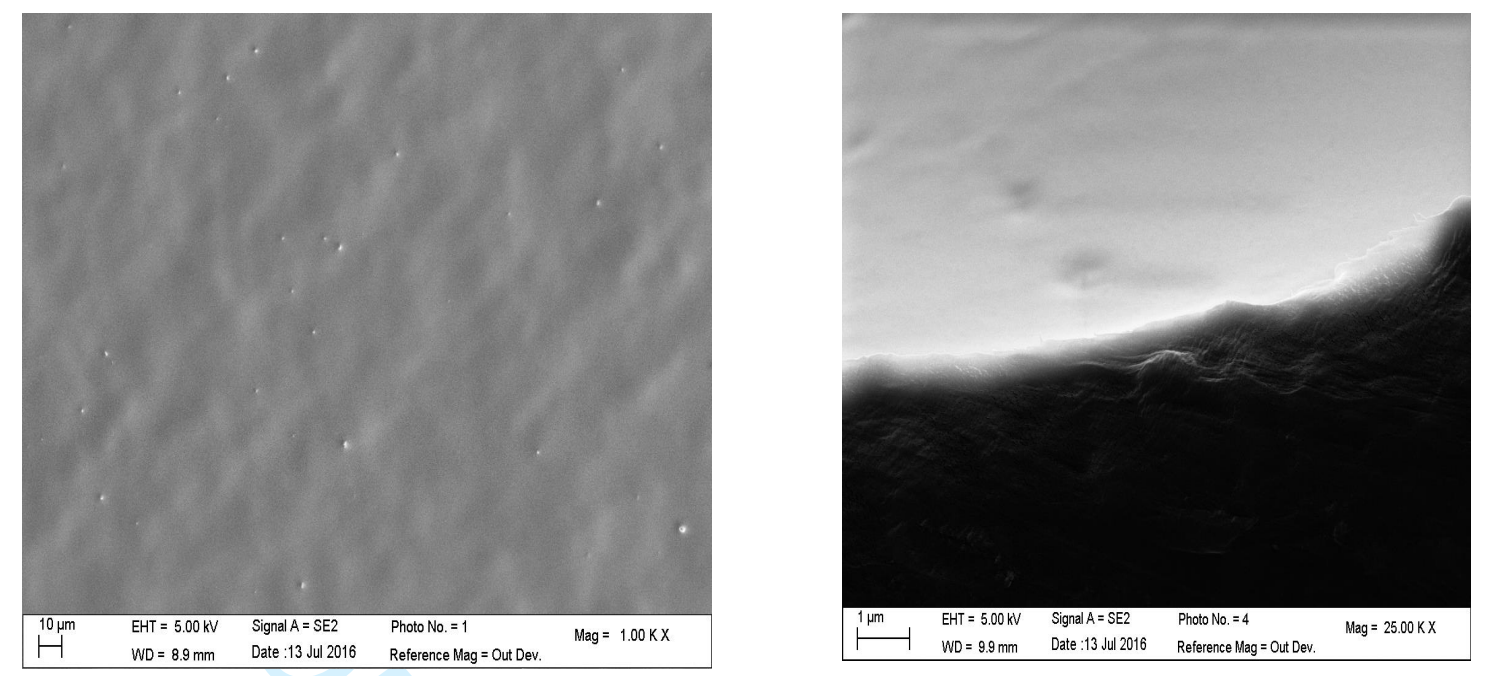

(b)
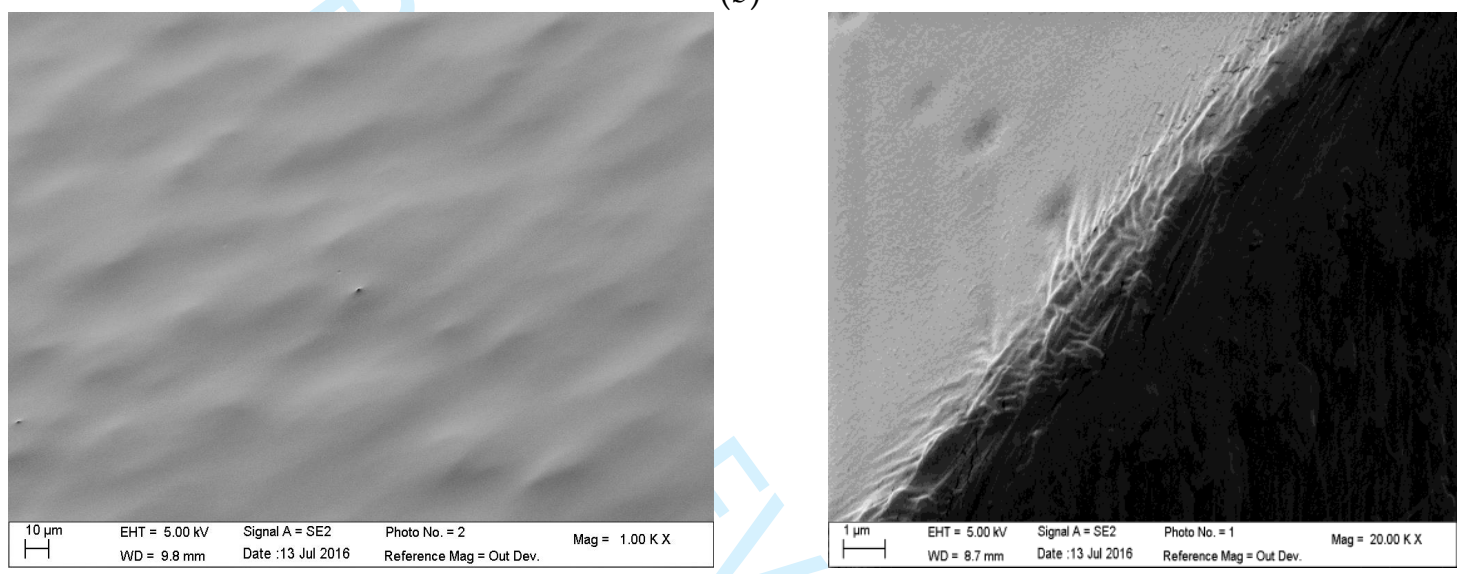

(c)

Figure 3. SEM images of the PEG coatings on the inner wall of the tube at a) $5 \mathrm{~cm}$ downstream, b) $25 \mathrm{~cm}$ downstream c) $65 \mathrm{~cm}$ downstream.

The surface wettability of the inner surface of PEG coated tubes was determined by sessile drop water contact angle measurements (Figure 4a), and compared to non-treated ones (Figure $4 b$ ). As can be clearly observed, the coated tube is completely hydrophilic inside.

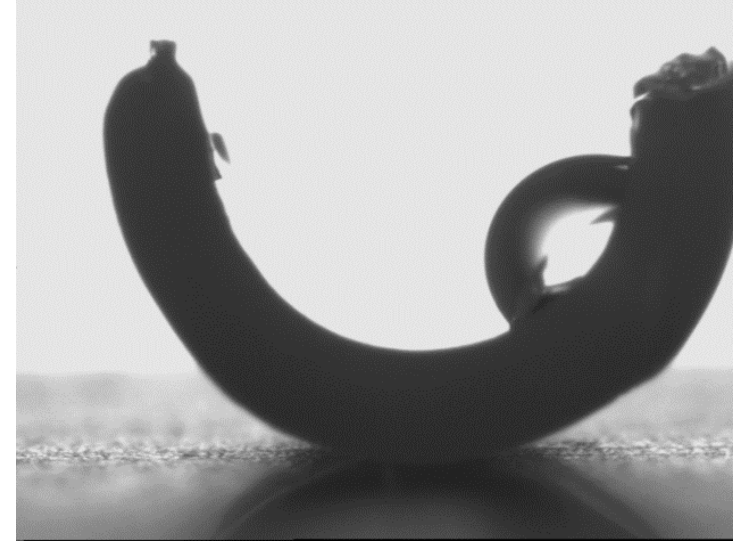

(a)

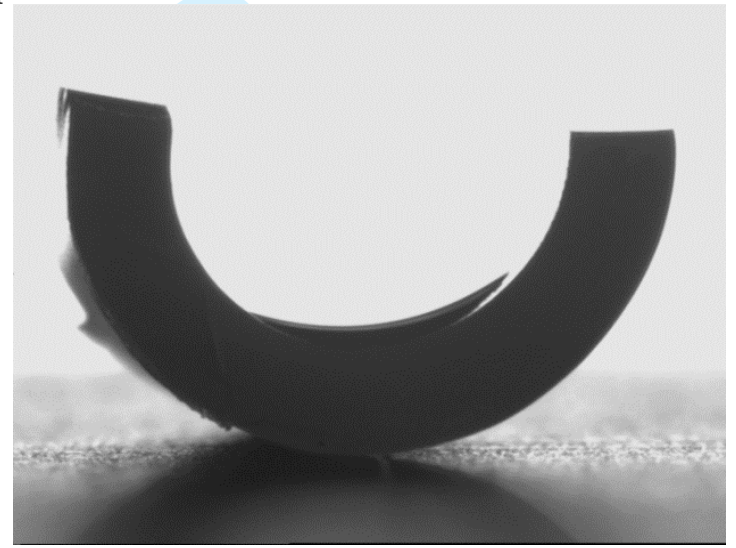

(b)

Figure 4. The wettability on the inner wall of the plasma treated HDPE tube $25 \mathrm{~cm}$ downstream (a). The volume of a droplet is $6 \mu$ l. The wettability on the untreated HDPE tubes surface is also shown (b).

Surface chemical analysis of the PEG coatings was carried out by XPS on different parts of the HDPE tube. It is known from the literature that it is possible to tune the concentration of the PEO character of the layer by controlling the plasma power and treatment time. It has been claimed that a 
concentration of the C-O-C groups equal to $70 \%$ and higher is required to obtain the non-fouling behavior by a low pressure plasma [21,22]. Nisol et al obtained a variable PEO character thin films ranging from 70 to $50 \%$ in a DBD system(I believe) the Consequently the protein repellent property was more pronounced for thin films characterized by a higher PEO character [23]. Also Blatter et al deposited PEO-like non fouling coatings with a Dielectric Barrier Discharge system [24]. A similar approach has been presented also by Choukourov et al. [25].

Bhatt et al compared the atmospheric plasma deposited PEG coatings with typical low pressure deposited PEG like coatings. Less retention of $\mathrm{C}-\mathrm{O}-\mathrm{C}$ and therefore less cell repellent properties were observed for atmospheric pressure coatings as compared to those deposited at low pressure. They showed the best cell repellent character in open-air condition was for a C-O-C ratio equal to $56.3 \%$ (Bhatt 2014).

As shown in Figure 5, the C1s XPS spectrum was de-convoluted into four different components attributed to $\mathrm{C}-\mathrm{C} / \mathrm{C}-\mathrm{H}, \mathrm{C}-\mathrm{OH} / \mathrm{C}-\mathrm{O}, \mathrm{C}=\mathrm{O}$ and $\mathrm{O}=\mathrm{C}-\mathrm{O}$. At $5 \mathrm{~cm}$ and $25 \mathrm{~cm}$ downstream (Figure 5(a) and (b)), the spectra show coatings rich in ether groups at $286.5 \mathrm{eV}$, showing the retention of EG structure in the deposited polymer coatings. Smaller contributions from aliphatic carbon as well as from the carbonyl- and carboxyl-based species are also typical for PEG-like plasma polymers.

In our experiments, it is worth noting that good retention $(5 \mathrm{~cm}=58 \%$ and $25 \mathrm{~cm}=60 \%)$ of the $\mathrm{C}-$ $\mathrm{O}-\mathrm{C}$ groups has been usually recognized as a prerequisite for the non-fouling behavior of the plasma polymers. For $45 \mathrm{~cm}$ and $65 \mathrm{~cm}$ downstream, the C-O-C/C1s surface area was smaller with a percentage of $45 \%$ and $40 \%$, respectively.

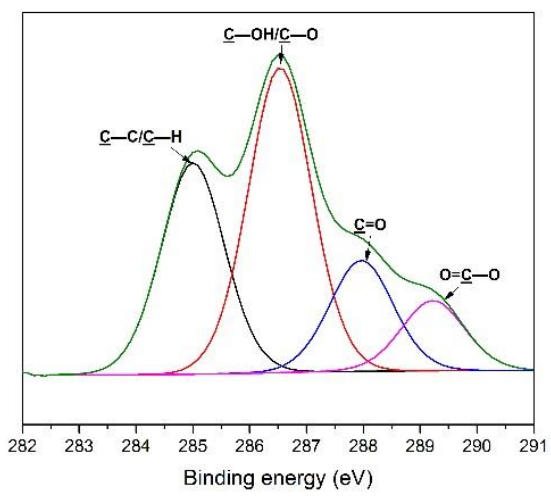

(a)

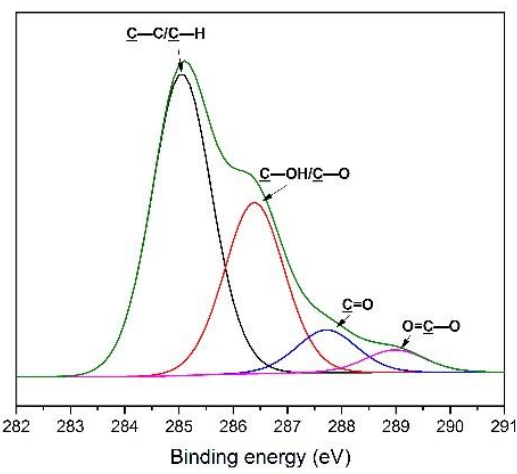

(c)

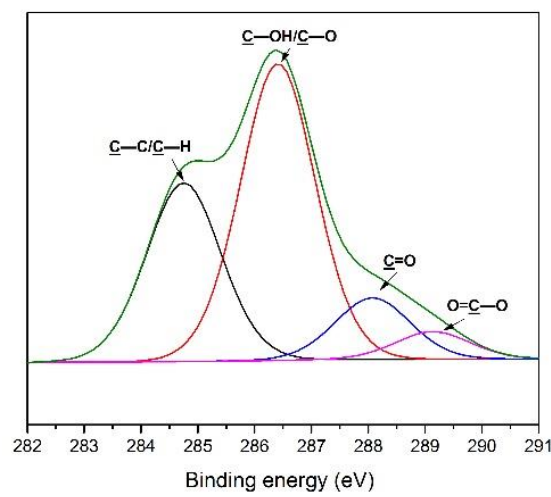

(b)

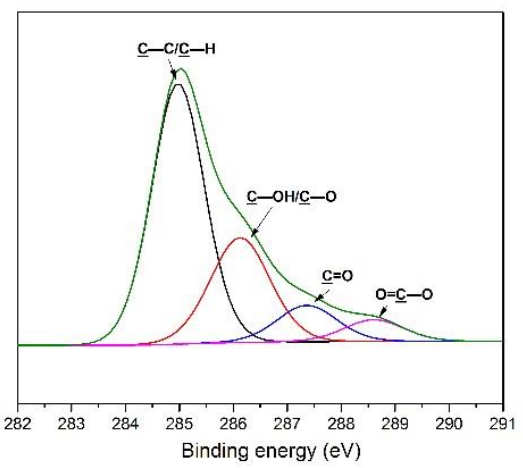

(d)

Figure 5. XPS spectra for plasma polymerized PEG inside the HDPE tube at different distances from the HV electrode (a) $5 \mathrm{~cm}$, (b) $25 \mathrm{~cm}$, (c) $45 \mathrm{~cm}$ and (d) $65 \mathrm{~cm}$.

Finally, the biological response to the plasma deposited PEG polymer surface was investigated in vitro using the CT-26 cell lines. For the biological tests, PEG coatings were deposited inside Pyrex tubes as mentioned in the experimental part, because of the nonadhesive character of the the untreated HDPE. 
The cell repellent behavior of the plasma deposited PEG coatings was attributed to the retention of the ethylene oxide functionalities. There exists a huge number of references which explain the antifouling effect of the ethylene oxide groups e.g. by providing a molecular basis for a water barrier layer which helps to reduce the cell adsorption on the surfaces. Bare (untreated) Pyrex tube showed a good adhesion of cells but on the PEG coatings most of the cells were detached from the tube.

The adherent cells were counted by using Image J software. For the image processing, four microscopic images were carried out on each coating and the resulting values of the adherent cells were averaged (Figure 6). As expected, there was less cell adhesion observed on plasma polymerized PEG coatings which were also stable after $24 \mathrm{~h}$ of cell culture. As the distance from the high voltage electrode increased, the cell repellent character decreased. More than $120000 \pm 9000$ cells were attached to the bare Pyrex tube while on the tubes with PEG coating deposited for the first piece of Pyrex tube $(5-25 \mathrm{~cm}$ downstream from the HV electrode), the second piece (25-45 cm downstream) and the third Pyrex piece

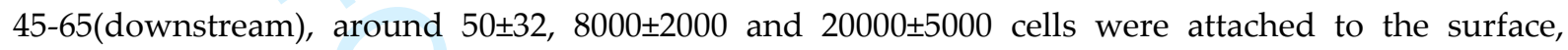
respectively. One can conclude that the number of cells observed on $5-25 \mathrm{~cm}$ pieces is much smaller than the other two coated pieces closer to the exit. This is probably due to the highest concentration of $\mathrm{C}-\mathrm{O}-\mathrm{C}$ groups observed in the case of $5-25 \mathrm{~cm}$ distance. The measurements show that at distance of 45-65 cm downstream of the tube, we probably have an effect of the surrounding air in the fragmentation of the DEGME precursor leading to coatings with less retention of ethyl groups which explains the decrease in the non-adhesive properties to CT-26 cells. These results show that although the whole $70 \mathrm{~cm}$ tube has not been coated homogeneously, due to the monomer depletion along the tube, the PEG coatings deposited up to $30 \mathrm{~cm}$ away from the electrode presents a good and homogeneous cell repellent properties.

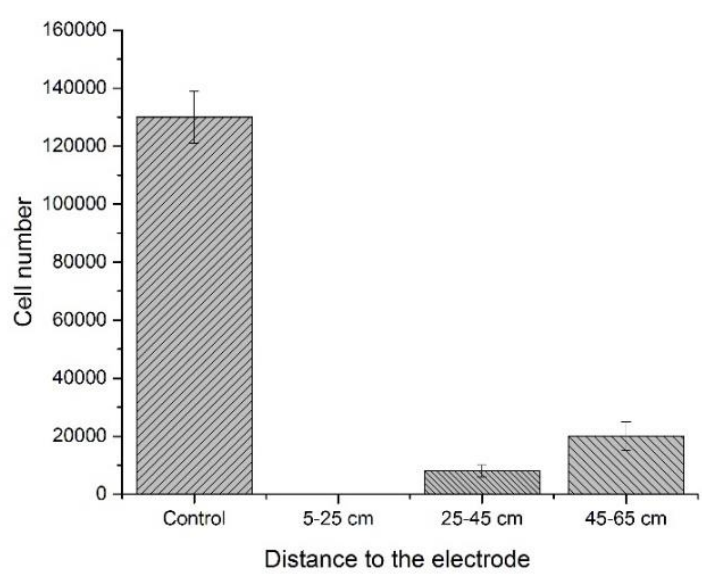

Figure 6. Cell adhesion properties of CT-26 on PEG coatings incubated for $24 \mathrm{~h}$ at different parts of Pyrex tube.

\section{Conclusions}

It has been pointed out that the long distance traveling plasma has the ability to deposit thin films at atmospheric pressure and low temperature. Plasma polymers were deposited by means of a transported discharge inside the HDPE and Pyrex tubes. The latter being a dry process, as compared to the conventional multistep wet chemical techniques, therefore overcome the disadvantage of incomplete removal of catalysts used in wet processes. The antifouling properties were tested by looking at the cell-surface interactions for biological applications, which were easier to see rather than to look at protein adsorption. The cell repellent or adhesive properties of the PEG coatings were evaluated by seeding CT-26 cell lines, which grow readily on films deposited inside tube at different parts of the tube i.e. closer to the HV electrode, closer to the exit or in between. From these results it can be concluded that the transporting discharge offers a great potential for modifying surface properties inside catheter tubes, used for evacuation of pathogen biological liquids. Our results have demonstrated 
that plasma polymerized PEG coatings can be tailored in such a way to be cell repellent, convenient for biomedical implants which can be used as anti-biofouling surfaces for urethral catheters, cardiac stents etc.

\section{References}

1. Jiang, N.; Qian, S. F.; Wang, L.; Zhang, H. X. Localized material growth by a dielectric barrier discharge. Thin Solid Films 2001, 390, 119-122.

2. Nisol, B.; Poleunis, C.; Bertrand, P. ; Reniers, F. Poly (ethylene glycol) Films Deposited by Atmospheric Pressure Plasma Liquid Deposition and Atmospheric Pressure Plasma-Enhanced Chemical Vapour Deposition: Process, Chemical Composition Analysis and Biocompatibility. Plasma process. polym. 2010, 7, 715725.

3. Da Ponte, G.; Sardella, E.; Fanelli, F.; Van Hoeck, A. ; d'Agostino, R.; Paulussen, S.; Favia, P. Atmospheric pressure plasma deposition of organic films of biomedical interest. Surf. Coat. Technol. 2011, 205, S525-S528.

4. De Geyter, N. ; Morent, R. ; Van Vlierberghe, S. ; Dubruel, P. ; Leys, C. ; Gengembre, L.; ... Payen, E. Deposition of polymethyl methacrylate on polypropylene substrates using an atmospheric pressure dielectric barrier discharge. Prog. Org. Coat. 2009, 64, 230-237.

5. Carton, O.; Ben Salem, D.; Bhatt, S.; Pulpytel, J.; Arefi-Khonsari, F. Plasma polymerization of acrylic acid by atmospheric pressure nitrogen plasma jet for biomedical applications. Plasma process. polym. 2012, 9, 984-993.

6. Merche, D.; Vandencasteele, N.; Reniers, F. Atmospheric plasmas for thin film deposition: A critical review. Thin Solid Films 2012, 520(13), 4219-4236.

7. Arefi. F; Andre, V; Montazer-Rahmati. P; Amouroux, J. Pure \& Appl. Chem. Vol. 64, No.5, pp.715-723, 1992.

8. Bogaerts, A.; Neyts, E.; Gijbels, R.; van der Mullen, J. Gas discharge plasmas and their applications. Spectrochim. Acta Part B At. Spectrosc. 2002, 57, 609-658.

9. Friedrich, J. Mechanisms of plasma polymerization-reviewed from a chemical point of view. Plasma process. polym. 2011, 8, 783-802.

10. Prat, R.; Koh, Y. J.; Babukutty, Y.; Kogoma, M.; Okazaki, S.; Kodama, M. Polymer deposition using atmospheric pressure plasma glow (APG) discharge. Polymer 2000, 41, 7355-7360.

11. Gordeev, I.; Šimek, M.; Prukner, V.; Artemenko, A.; Kousal, J.; Nikitin, D.; ... Biederman, H. Deposition of Poly (Ethylene Oxide)-Like Plasma Polymers on Inner Surfaces of Cavities by Means of Atmospheric-Pressure SDBD-Based Jet. Plasma process. polym. 2016, 13, 823-833.

12. Harris, J. M.; Zalipsky, S. Polyethylene Glycol: Chemistry and Biological Applications. Washington, DC: ACS, $1997,680,155-169$.

13. Yu, Q.; Zhang, Y.; Wang, H.; Brash, J.; Chen, H. Anti-fouling bioactive surfaces. Acta biomater. 2011, 7(4), 15501557.

14. Knop, K.; Hoogenboom, R.; Fischer, D; Schubert, U. S. Poly (ethylene glycol) in drug delivery: pros and cons as well as potential alternatives. Ange. Chem. Int. Ed. 2010, 49, 6288-6308.

15. Bhatt, S.; Pulpytel, J.; Arefi-Khonsari, F. Low and atmospheric plasma polymerisation of nanocoatings for bioapplications. Surf. Innov. 2015, 3, 63-83.

16. Bhatt, S.; Pulpytel, J.; Mirshahi, M.; Arefi-Khonsari, F. Catalyst-free plasma-assisted copolymerization of poly ( $\varepsilon$-caprolactone)-poly (ethylene glycol) for biomedical applications. ACS Macro Lett. 2012, 1(6), 764-767.

17. Bhatt, S.; Pulpytel, J.; Mori, S.; Mirshahi, M.; Arefi-Khonsari, F. Cell Repellent Coatings Developed by an Open Air Atmospheric Pressure Non-Equilibrium Argon Plasma Jet for Biomedical Applications. Plasma process. polym. 2014, 11, 24-36.

18. Da Ponte, G.; Sardella, E. ; Fanelli, F. ; d'Agostino, R. ; Gristina, R. ; Favia, P. Plasma Deposition of PEO-Like Coatings with Aerosol-Assisted Dielectric Barrier Discharges. Plasma process. polym. 2012, 9, 1176-1183.

19. Gordeev, I.; Choukourov, A.; Šimek, M.; Prukner, V.; Biederman, H. PEO-like Plasma Polymers Prepared by Atmospheric Pressure Surface Dielectric Barrier Discharge. Plasma process. polym. 2012, 9, 782-791.

20. Omran, A. V.; Sohbatzadeh, F.; Siadati, S. N.; Colagar, A. H.; Akishev, Y.; Arefi-Khonsari, F. Single channel atmospheric pressure transporting plasma and plasma stream demultiplexing: physical characterization and application to E. coli bacteria inactivation. J. Phys. D: Appl. Phys. 2017, 50(31), 315202. 
21. Sardella, E.; Gristina, R.; Ceccone, G.; Gilliland, D.; Papadopoulou-Bouraoui, A.; Rossi, F.; ... d'Agostino, R. Control of cell adhesion and spreading by spatial microarranged PEO-like and pdAA domains. Surf. Coat. Technol. 2005, 200, 51-57.

22. Brétagnol, F.; Kylián, O.; Hasiwa, M.; Ceriotti, L.; Rauscher, H.; Ceccone, G.; ... Rossi, F. Micro-patterned surfaces based on plasma modification of PEO-like coating for biological applications. Sens. Actuators B: Chem. 2007, 123, 283-292.

23. Nisol, B.; Poleunis, C.; Bertrand, P.; Reniers, F. Poly (ethylene glycol) Films Deposited by Atmospheric Pressure Plasma Liquid Deposition and Atmospheric Pressure Plasma-Enhanced Chemical Vapour Deposition: Process, Chemical Composition Analysis and Biocompatibility. Plasma process. polym. 2010, 7, 715725 .

24. Blättler, T. M.; Pasche, S.; Textor, M.; Griesser, H. J. High salt stability and protein resistance of poly (L-lysine)g-poly (ethylene glycol) copolymers covalently immobilized via aldehyde plasma polymer interlayers on inorganic and polymeric substrates. Langmuir 2006, 22, 5760-5769.

25. Choukourov, A.; Gordeev, I.; Arzhakov, D.; Artemenko, A.; Kousal, J.; Kylián, O.; ... Biederman, H. Does Cross-Link Density of PEO-Like Plasma Polymers Influence their Resistance to Adsorption of Fibrinogen?. Plasma process. polym. 2012, 9, 48-58. 